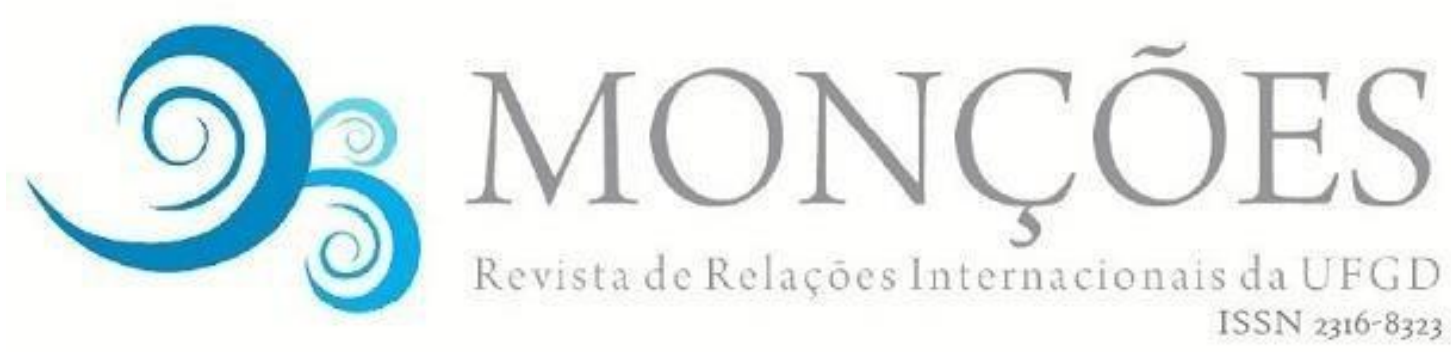

\title{
AS MULHERES NA CARREIRA DIPLOMÁTICA BRASILEIRA: CONSIDERAÇÕES SOBRE ADMISSÃO, HIERARQUIA E ASCENSÃO PROFISSIONAL
}

\author{
MARIANA COCKLES \\ Mestra (UFPE) e Doutoranda em Ciência Política (UFMG), bolsista CAPES \\ ANDREA QUIRINO STEINER \\ Professora Adjunta e Chefe do Departamento de Ciência Política da UFPE
}

\begin{abstract}
RESUMO: Este trabalho foca nas experiências e desafios particulares das mulheres na carreira diplomática brasileira. Através de entrevistas e análise documental, apresentamos uma descrição original sobre o processo de concessão de promoções na carreira e dos principais eventos recentes que culminaram em mudanças práticas na organização do Itamaraty. Discutimos, então, a instituição e implementação de cotas informais criadas durante a gestão do ex-chanceler Celso Amorim, bem como a criação e funcionamento do Comitê Gestor de Gênero e Raça. Neste contexto, identificamos que a organização informal das diplomatas é o principal canal de construção e visibilização da agenda comum das mulheres da carreira. Também verificamos que a demanda por reconhecimento das experiências de discriminação e das barreiras enfrentadas na progressão da carreira são os pontos mais sensíveis nesta agenda e que o exemplo das cotas demonstrou que a sobrevivência de regras para compensar os efeitos da desigualdade na carreira depende de sua formalização.
\end{abstract}

PALAVRAS-CHAVE: Itamaraty; diplomacia; desigualdade de gênero.

\section{WOMEN IN THE BRAZILIAN DIPLOMATIC SERVICE: CONSIDERATIONS ON ADMISSION, HIERARCHY AND PROFESSIONAL ASCENSION}

\begin{abstract}
This paper focuses on the experiences and specific challenges that Brazilian female diplomats face. Through interviews and documental analysis, we present an original description of the procedures for granting promotions in this career and of the main recent events that culminated in practical changes within Itamaraty. We then discuss the implementation of informal quotas during the former chancellor Celso Amorim's term, as well as the creation and operation of the Gender and Race Managing Committee. We find that female diplomats' informal organization is the main channel towards constructing and making visible a common agenda of women in the Brazilian diplomatic career. We also verified that the demand that discrimination experiences be acknowledged and the barriers faced regarding professional ascension are the most sensitive items in the agenda, and that the example of quotas showed that the survival of rules to compensate inequality depends on their formalization.
\end{abstract}

KEYWORDS: Itamaraty; diplomacy; gender inequality. 


\section{Introdução}

Este artigo discute a participação das mulheres na carreira diplomática brasileira, apresentando uma análise exploratória e descritiva sobre a evolução institucional da visibilidade da questão de gênero dentro do ministério em anos recentes. Na seção seguinte à esta introdução, reportamos as fontes e os métodos empregados para a coleta das informações utilizadas. Em seguida, apresentamos uma discussão histórica sobre a evolução do processo admissional na carreira, com ênfase nas principais características, avanços e retrocessos para a inclusão de mulheres no quadro de diplomatas. A quarta seção sumariza o processo complexo de concessão de promoções, discutindo os impactos prováveis de seu desenho atual sobre a desproporção de gênero nas classes mais altas da hierarquia funcional da carreira. Finalmente, apresentamos uma descrição dos principais eventos recentes, responsáveis pelo aumento da visibilidade da experiência e demandas por inclusão das mulheres na carreira; quais sejam, a implementação de cotas informais para as promoções, a organização informal das mulheres em torno de uma agenda comum de interesses e a criação do Comitê Gestor de Gênero e Raça do Itamaraty.

A desproporção crescente de gênero ao longo das classes da carreira parece resultar da intricada relação entre instituições formais e informais e os fatores de autoridade e cultura sobre os quais se baseia a socialização dentro do Ministério das Relações Exteriores (MRE). Nesse sentido, a ausência de critérios formais e, por consequência, o espaço de discricionariedade que os diplomatas têm dentro do sistema de promoções confere barreiras específicas para o acesso das mulheres às classes mais altas.

Também observamos que a iniciativa de implementação das cotas informais de gênero no processo de concessão de promoções foi eficiente, mas também descontínua, indicando que a ausência de formalização de incentivos e constrangimentos determinou sua fragilidade institucional. Por fim, identificamos que a organização informal das mulheres se apresenta tanto como o canal principal para a construção de uma agenda de interesses comuns das diplomatas, quanto como via de pressão e manifestação das demandas dentro do ambiente profissional. 


\section{Dados e métodos}

Um dos maiores desafios à elaboração de estudos sobre a participação das mulheres na carreira diplomática diz respeito à disponibilidade de dados. Diante da escassez de informações sobre o tema, optamos por realizar uma análise qualitativa, de caráter exploratório e descritivo. Para coletar as informações, realizamos entrevistas e uma análise documental dos Anuários do Instituto Rio Branco, de 2013 a 2015; do Decreto ํㅜ 6.559, de 8 de setembro de 2008, que regulamenta o processo de concessão de promoções; e de dois documentos elaborados pela organização informal das mulheres da carreiras uma carta entregue em 2012 à Secretaria do Serviço Exterior Brasileiro (SEB) e uma compilação de 102 relatos anônimos de assédios sofridos pelas diplomatas durante o exercício de suas funções.

Enquanto a discussão sobre a evolução do processo admissional na carreira utiliza as informações extraídas dos Anuários do Instituto Rio Branco (IRBr), as discussões das demais seções baseiam-se nas informações coletadas a partir das entrevistas. No total, foram treze diplomatas entrevistadas - oito individualmente ${ }^{1}$ e cinco através de um grupo focal de Terceiras-Secretárias. As entrevistas foram semiestruturadas e duraram, em média, uma hora e trinta minutos.

Todas as conversas foram gravadas, com consentimento das participantes, e armazenadas digitalmente. Alguns dos relatos são citados indiretamente, com atenção para preservar a identidade de todas as participantes. O grupo de Terceiras-Secretárias foi formado para coletar as opiniões de diplomatas que ainda se encontram na base da hierarquia funcional; foram discutidas expectativas sobre a trajetória na carreira e opiniões sobre 0 tratamento recente do Ministério à questão de gênero.

Além disso, foi realizada uma entrevista semiestruturada com o exchanceler Celso Amorim, devido ao seu protagonismo na implementação das cotas informais para as mulheres no processo de concessão de promoções. Sua reprodução foi autorizada pelo mesmo e a discussão foi conduzida por um roteiro

\footnotetext{
${ }^{1}$ As oito diplomatas entrevistadas individualmente dividiram-se da seguinte maneira: duas Terceiras-Secretárias, uma Segunda-Secretária, três Primeiras-Secretárias, uma Conselheira e uma Ministra de Segunda-Classe.
} 
distinto daquele empregado nas demais entrevistas. $O$ embaixador relatou como surgiu a preocupação em investir na promoção de mais mulheres e como as cotas foram implementadas durante sua gestão.

É importante mencionar que a descrição do processo de institucionalização do Comitê Gestor de Gênero e Raça do MRE foi elaborada em grande medida com base nas entrevistas, mas que os trechos da seção relacionada a esta discussão não citam as entrevistadas discriminadamente, devido à sensibilidade do assunto e à necessidade de preservar suas identidades.

\section{O processo admissional da carreira}

Um ano após a criação do Instituto Rio Branco, foi instituído o Curso de Preparação à Carreira de Diplomata (CPCD), através do Decreto-Lei no 9.032/1946, cujo acesso dava-se por aprovação em exame vestibular. Aos candidatos aprovados, era exigida a conclusão do CPCD, que era oferecido pelo $\mathrm{IRBr}$, sediado no então distrito federal do Rio de Janeiro. A admissão, portanto, era indireta ${ }^{2}$. Após a conclusão, o aluno era finalmente admitido no serviço exterior como Terceiro-Secretário e passava a receber os vencimentos correspondentes à carreira.

As provas eram realizadas no Rio de Janeiro e só a partir de 1959 o exame passou a ser aplicado nas capitais mais populosas dos estados brasileiros. A mudança foi acompanhada pelo Exame de Seleção Prévia, que corresponderia, posteriormente, ao Teste de Pré-Seleção ou à atual Primeira Fase do Concurso de Admissão à Carreira de Diplomata (CACD).

No ano de 1995, o CPCD foi substituído pelo Programa de Formação e Aperfeiçoamento - Primeira Fase (PROFA-I), que regulou o conteúdo das disciplinas de acordo com as exigências específicas da rotina de trabalho. No ano seguinte, o antigo exame de vestibular do CPCD foi também substituído, dando lugar ao CACD, que manteve o formato da estrutura curricular do CPCD, à exceção de pequenas alterações.

2 Durante os 50 anos de duração do CPCD, foram realizados apenas sete concursos de aprovação direta, nos anos de 1954, 1955, 1962, 1967, 1975, 1977 e 1978. 
Outra mudança importante foi a substituição do PROFA-I pelo atual Curso de Formação do Instituto Rio Branco, em 2003. O curso passou a ofertar o Mestrado Profissionalizante em Diplomacia como requisito para estágio no exterior, sendo dispensados, facultativamente, os candidatos aprovados no CACD já mestres ou doutores. Em 2014, a Portaria no 179 tornou, novamente, a conclusão do Curso de Formação do $\mathrm{IRBr}$ requisito obrigatório a todos os candidatos, vigorando atualmente.

Segundo o último edital do $\mathrm{CACD}^{3}$, o exame é composto por três fases realizadas nas capitais de todos os estados brasileiros. Nas edições de 2011 a 2014, a primeira fase do CACD contou com a reserva de $10 \%$ das vagas para candidatos negros. Esse percentual aumentou para $20 \%$ e se estendeu para todas as fases do exame, a partir da promulgação da Lei ㄲo 12.990/2014.

No Gráfico 1, é possível visualizar a proporção das mulheres que entraram nas turmas do IRBr por década, desde os anos 1950 até os anos 2010; observase que a participação das mulheres na entrada da carreira sofreu uma leve queda nos anos 1990, mas logo retomou a tendência de crescimento nas décadas seguintes.

Segundo Farias e Carmo (2016), atualmente as mulheres correspondem a, aproximadamente, $40 \%$ dos candidatos e a menos de $25 \%$ dos aprovados do CACD; de acordo com a projeção dos dados de 1954 a 2010, a tendência do ritmo de entrada de mulheres indica que a igualdade entre gêneros no quadro diplomático só será atingida em 2066. E essa estimativa, alertam os autores, ainda carrega certa medida de otimismo, pois conta com o aumento (ou pelo menos a manutenção) da valorização da cultura de igualdade de gênero de anos recentes. $O$ Gráfico 2 mostra como essa tendência se apresenta nas últimas décadas. A tendência linear de crescimento para o período é similar quando comparada à do intervalo de 1954 a 2015 e seus coeficientes de determinação são igualmente baixos; $R^{2}=0,25$ para todo o intervalo e $R^{2}=0,22$ para o período de referência do gráfico.

Estudos anteriores sobre a participação das mulheres na diplomacia brasileira apontam que existem duas explicações possíveis sobre o gap de

${ }^{3}$ Edital no 1 de junho de 2016. 
gênero na entrada da carreira (BALBINO, 2011; DELAMONICA, 2014; FARIAS \& CARMO, 2016). A primeira diz respeito à formulação das provas de seleção do CACD e à possibilidade de que o processo de seleção não seja neutro. Farias e Carmo (2016) lembram que a elaboração de questões em testes de seleção geralmente tende a favorecer certas características individuais e vários estudos já demonstraram que esse viés termina prejudicando determinados grupos sociais nas seleções, inclusive as mulheres (BRELAND et al., 1999; KIZILCA, 2013; PIFFER et al., 2014).

A segunda explicação teria raiz na divisão sexual do trabalho e na socialização dos papeis de gênero. A participação das mulheres em carreiras e posições tradicionalmente masculinas conta com uma barreira que antecede até mesmo o processo de recrutamento: o sentimento de "não pertencer àquele espaço" e as baixas perspectivas de sucesso desestimulam a candidatura feminina (HOYTI, 2005). No caso da diplomacia, as mulheres enfrentam, ainda, as expectativas do custo familiar para investimento na carreira, calculado geralmente pelos estigmas da perda da feminilidade e da alta correlação entre a progressão e os divórcios e a abdicação da vida familiar, por conta da instabilidade das remoções.

\section{Gráfico 1. Proporção de mulheres nas turmas do IRBr por década (1953-} 2015)

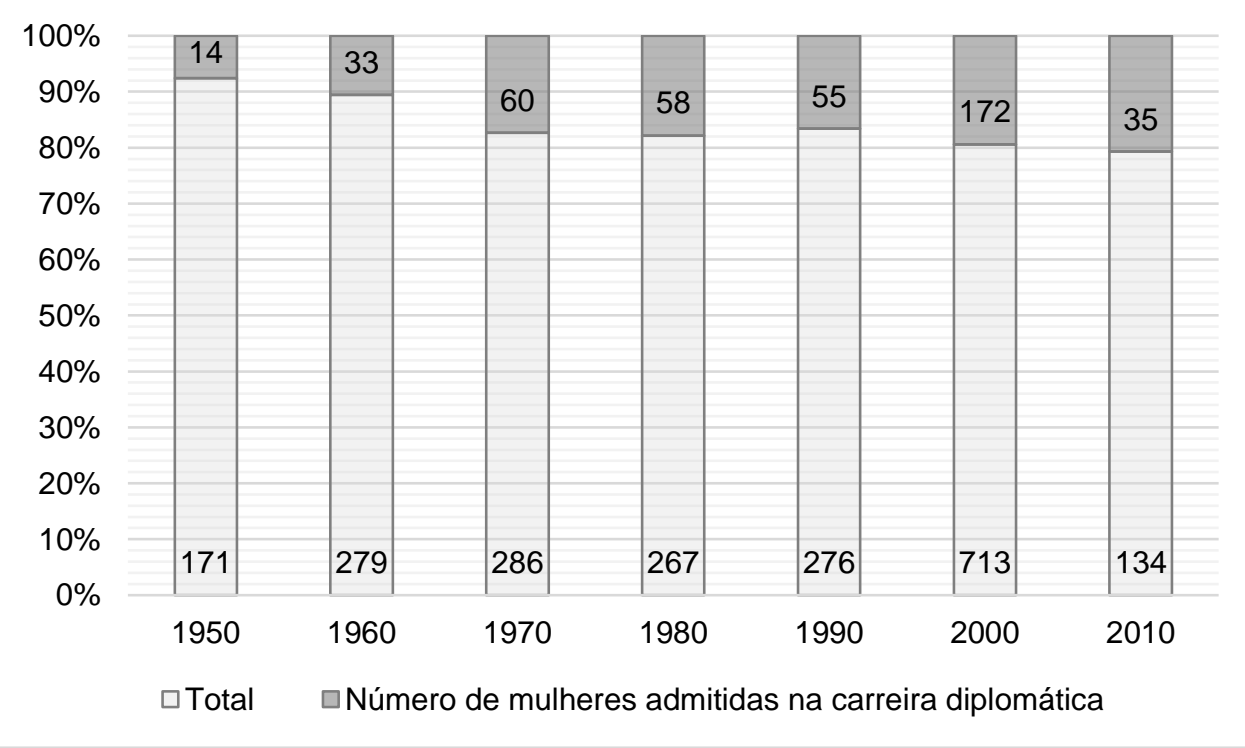

Fonte: IRBr, 2016. Elaboração própria. 


\section{Gráfico 2. Evolução recente da participação feminina (1998-2015)}

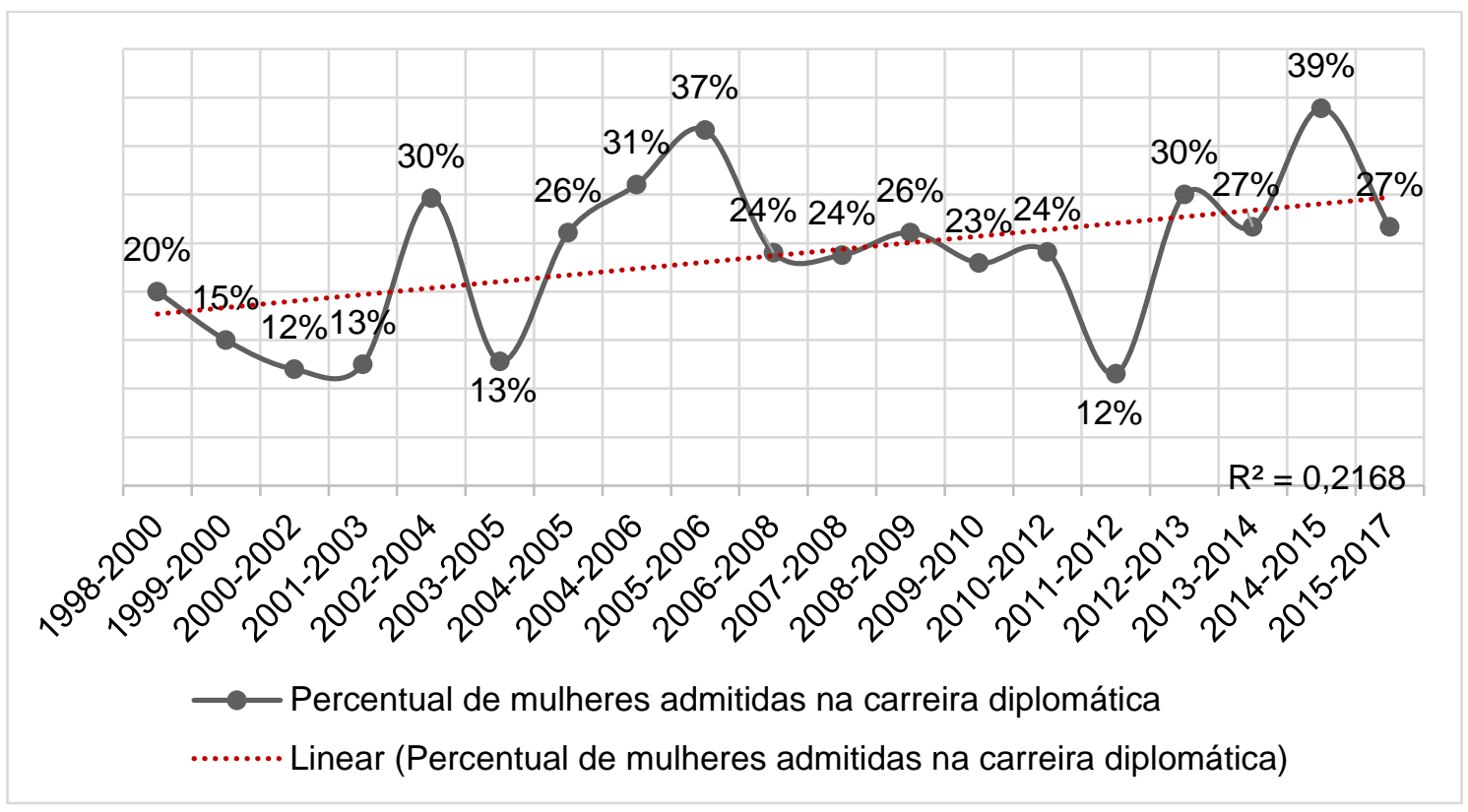

Fonte: $\mathrm{IRBr}$, 2016. Elaboração própria.

Até o momento, nenhuma pesquisa dispôs de dados suficientes para trazer evidências sobre a primeira explicação, mas os trabalhos de Balbino (2011) e Delamonica (2014) sugerem que as características da carreira afastem mesmo o interesse das mulheres. Essa condição seria ainda mais reforçada pelo processo de incorporação dos candidatos aprovados na seleção.

Moura (2007) aponta, ainda, que a entrada na carreira é marcada pela construção da identidade do diplomata. A autora observa que, para os candidatos bem-sucedidos no CACD, a aprovação e entrada no Ministério representa, antes de tudo, a aquisição de uma condição social de poder muito específica à classe dos diplomatas e ao imaginário histórico que a define. Contudo, como também observa Dulci (2008), assim que os candidatos iniciam a carreira, esse imaginário é rapidamente substituído por dois elementos que baseiam "a identidade própria da função": a formalidade e a hierarquia. 


\section{Hierarquia e ascensão profissional}

Segundo Moura (2007), a peculiaridade da hierarquia da carreira diplomática, responsável pela distinção do Itamaraty das demais agências executivas do governo, resulta de uma estrutura institucional que combina elementos tradicionais da burocracia nacional (organizada em cargos e funções) à escalonagem das Forças Armadas (organizada sobre "patentes"). Esta combinação oferece um senso forte de estratificação para os diplomatas e o pertencimento a cada categoria determina o status não só na estrutura funcional, mas também nas socializações dentro do Ministério (MOURA, 2007). Tal hierarquia é delimitada por classes e cada promoção corresponde à ascensão do diplomata para a classe subsequente. A Figura 1 ilustra, grosso modo, o processo de progressão na carreira e as seis classes que a compõem.

Quando o candidato aprovado no CACD é admitido como funcionário do SEB, entra como Terceiro-Secretário. Após o período mínimo de três (e máximo de quatro) anos de serviço efetivo, caso o diplomata tenha concluído o Curso de Formação, a promoção para a classe de Segundo-Secretário acontece automaticamente, de acordo com a disponibilidade de vagas e respeitando a ordem decrescente de tempo de serviço efetivo.

A partir da classe de Segundo-Secretário, todas as promoções são sujeitas não só a requisitos de antiguidade, mas também a critérios de merecimento. 
Figura 1. Classes de hierarquia da carreira brasileira de diplomata

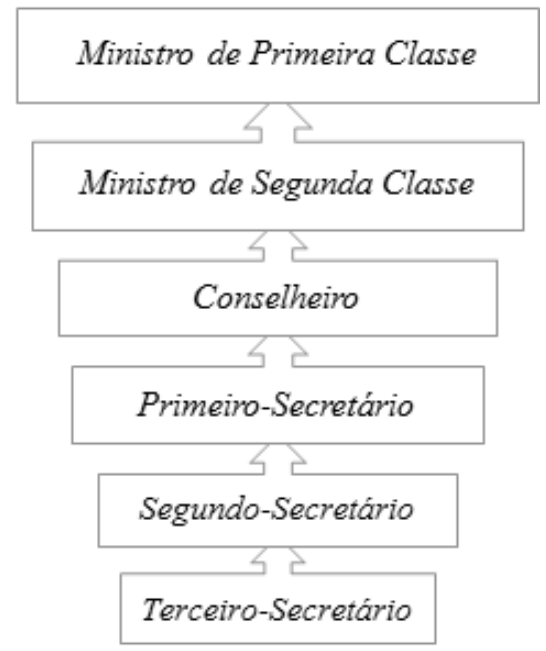

As promoções acontecem duas vezes ao ano, quando os diplomatas são listados em um documento denominado Lista de Antiguidade (LA). Na Lista, constam todas as informações que permitem verificar se os diplomatas cumprem os requisitos de elegibilidade; a Tabela 1 resume os critérios práticos para cada classe.

Tabela 1. Critérios de habilitação para promoções na carreira de diplomata

\begin{tabular}{c|c|c|c|c}
\hline \multirow{2}{*}{ Classe } & Antiguidade & \multicolumn{3}{|c}{ Merecimento } \\
\cline { 2 - 5 } & $\begin{array}{c}\text { Tempo de } \\
\text { efetivo serviço }\end{array}$ & $\begin{array}{c}\text { Tempo de } \\
\text { serviço no } \\
\text { exterior }\end{array}$ & $\begin{array}{c}\text { Tempo de } \\
\text { exercício de } \\
\text { funções de } \\
\text { chefia }\end{array}$ & $\begin{array}{c}\text { Conclusão de } \\
\text { cursos }\end{array}$ \\
\hline $\begin{array}{c}\text { Ministro de } \\
\text { Primeira } \\
\text { Classe }\end{array}$ & 20 anos & 10 anos & 3 anos & - \\
\hline $\begin{array}{c}\text { Ministro de } \\
\text { Segunda } \\
\text { Classe }\end{array}$ & 15 anos & $\begin{array}{c}7 \text { anos e } 6 \\
\text { meses }\end{array}$ & - & $\begin{array}{c}\text { CAE - Curso de } \\
\text { Altos Estudos }\end{array}$ \\
\hline $\begin{array}{c}\text { Conselheiro } \\
\text { Primeiro- }\end{array}$ & 10 anos & 5 anos & - & $\begin{array}{c}\text { CAP - Curso de } \\
\text { Atualização em } \\
\text { Política Externa }\end{array}$ \\
\hline Secretário & 3 anos & 2 anos & - & $\begin{array}{c}\text { CAD - Curso de } \\
\text { Aperfeiçoamento } \\
\text { de Diplomatas }\end{array}$ \\
\hline \hline
\end{tabular}

Fonte: Decreto nº 6.559/2008. Elaboração própria. 
Os postos no exterior são classificados em quatro categorias, de A a D, "segundo o grau de representatividade da missão e as condições específicas de vida na sede" (Artigo 13 do Decreto oㅜ 93.325/1986). Para fins de promoção, caso o diplomata complete pelo menos um ano de serviço efetivo, o tempo em postos $C$ é computado em dobro e em postos $D$, em triplo.

O tempo de serviço em funções de chefia, por sua vez, é contabilizado quando o diplomata assume a titularidade desse tipo de função, a nível mínimo de DAS-4 ${ }^{4}$ na Secretaria de Estado das Relações Exteriores (SERE) ou em um posto no exterior. Este critério só aparece como requisito para os Ministros de Segunda Classe que desejam ascender. Por fim, vale observar que os diplomatas devem ter pelo menos três anos de efetivo serviço na classe em que se encontram para que possam ascender à subsequente.

Além dos critérios de antiguidade, essas promoções são condicionadas à conclusão de cursos de treinamento e qualificação. Todos os cursos são ofertados e coordenados pelo Instituto e se assemelham a cursos de pósgraduação.

Os diplomatas habilitados para receber as promoções, então, concorrem à entrada para o Quadro de Acesso (QA), que determina quem pode receber as promoções naquele semestre - apenas os diplomatas que constam no QA recebem as promoções para as vagas. Este processo acontece em cinco etapas (Figura 2)

As cinco etapas envolvem a participação (1) do Departamento do Serviço Exterior, (2) de todo o quadro de diplomatas, (3) da Câmara de Avaliação II (4), da Câmara de Avaliação I e da (5) Comissão de Promoções, respectivamente. A composição das Câmaras e da Comissão pode ser visualizada na Tabela 2. Ambas as Câmaras de Avaliação são presididas pelo Secretário-Geral das Relações Exteriores e têm como Secretário-Executivo o Diretor do Departamento do Serviço Exterior (DSE). Já em relação à Comissão, quem a preside é o Ministro de Estado em exercício.

${ }^{4}$ Os cargos comissionados de Direção e Assessoramento Superior (DAS) da administração pública direta, autárquica e fundacional são classificados em seis níveis, no Brasil. 
Primeiro, os diplomatas realizam as votações horizontais e verticais a partir das informações na LA. As horizontais correspondem àquelas que são realizadas pelos pares. Já as votações verticais são realizadas pelos diplomatas Ministros de Primeira e Segunda Classe, Conselheiros e Primeiros-Secretários, que indicam os nomes para o QA de todas as classes inferiores. As indicações em todas as etapas de votação devem ser feitas em um número que equivale a um décimo dos cargos de cada classe.

$O$ regimento das promoções determina um sistema de contagem de pontos para os diplomatas mais bem votados e os resultados das votações horizontais são unidos aos resultados das votações verticais para compor uma segunda lista ranqueada (Etapa 2, na Figura 1). Em paralelo, a Câmara de Avaliação II também utiliza as informações da LA para realizar votações majoritárias internas que resultam em uma terceira lista dos diplomatas merecedores de exame pela Câmara de Avaliação I para concorrerem ao QA (Etapa 3).

Esta, por sua vez, utiliza como referência as listas que resultaram das votações e da etapa da Câmara de Avaliação II para filtrar novamente os diplomatas que vão concorrer às promoções (Etapa 4). A decisão final sobre o QA é dada pela Comissão de Promoções, que utiliza como base a lista resultante das votações nominais da Câmara de Avaliação I (Etapa 5). Nesta última fase, a Comissão determina os critérios de seleção e, por fim, escolhem pelo voto majoritário os diplomatas que irão compor o Quadro de Acesso. A partir da lista final do Quadro, são indicados os diplomatas que vão preencher as vagas disponíveis. 
Figura 2. Processo de elaboração do Quadro de Acesso

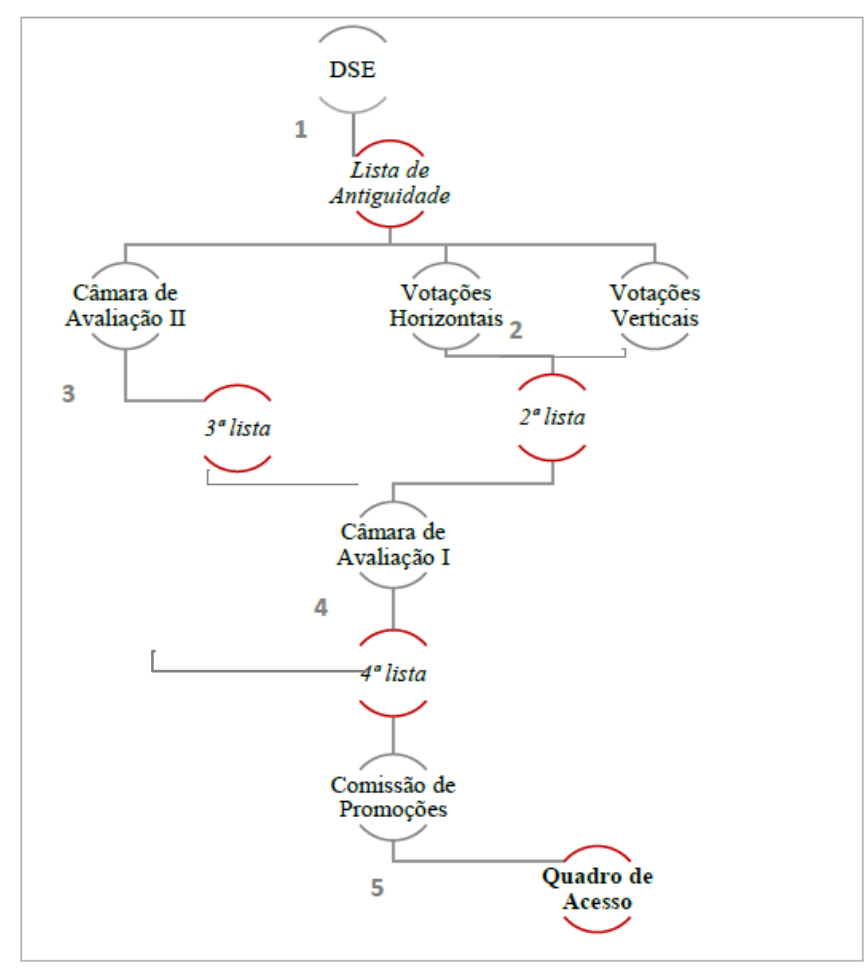

Fonte: Decreto no 6.559/2008. Elaboração própria.

Tabela 2. Composição das Câmaras de Avaliação e da Comissão de Promoções

Câmara de Avaliação II

Câmara de Avaliação I

Comissão de Promoções
Diplomatas que ocupam chefia na SERE e que não integram a Comissão de Promoções nem a Câmara de Avaliação I.

Chefe de Gabinete do Ministro de Estado; Chefe de Gabinete do Secretário-Geral; Chefe do Cerimonial; Inspetor-Geral do SEB; Secretário de Controle Interno; Chefe da Assessoria Especial de Assuntos Federativos e Parlamentares; Corregedor do SEB; Secretário de Planejamento Diplomático; Diretores e Assessores Especiais do Gabinete.

Ministro de Estado das Relações Exteriores;

Secretário-Geral das Relações Exteriores; Subsecretários-Gerais; Diretor-Geral do IRBr; Chefe de Gabinete do Ministro de Estado; Chefe de Gabinete do Secretário-Geral e um MPC no exercício de chefia em posto e convocado pelo Ministro de Estado.

Fonte: Decreto № 6.559/2008. Elaboração própria. 
Preenchendo os requisitos, todos os diplomatas que constam no quadro ordinário do SEB podem concorrer à entrada no QA. Porém cada classe da carreira possui uma delimitação temporal de permanência dos servidores no quadro ordinário; ultrapassado esse limite, o diplomata entra no quadro especial (QE) do SEB. Para os Ministros de Primeira e Segunda Classe, assim como os Conselheiros, esse limite corresponde à permanência na mesma classe por até 15 anos ou até a idade máxima estabelecida por lei para cada classe. Por sua vez, os Segundos e Primeiros-Secretários, após o período mínimo de 12 anos, entram para o quadro especial de acordo com a ordem decrescente de tempo de efetivo.

Havendo disponibilidade, os diplomatas do quadro especial concorrem a uma vaga na classe subsequente. Porém, como observam Farias e Carmo (2016), a entrada para o QE diminui consideravelmente a probabilidade de que o diplomata seja promovido. Além disso, os Ministros de Segunda Classe do QE não podem ascender a Ministros de Primeira Classe. Ou seja, a chegada ao topo da carreira só se dá pelas vias normais do quadro ordinário do SEB.

Em relação à composição dos quadros, observamos que, em 2015, as mulheres corresponderam a apenas $22,9 \%$ dos diplomatas e que essa diferença entre gêneros sobe ainda mais quando observamos a metade superior da hierarquia funcional; por exemplo, dos 199 embaixadores, apenas 18,6\% são mulheres ${ }^{5}(\mathrm{IRBr}, 2016)$. Não é raro ouvir nos corredores do Itamaraty que a subrepresentação feminina nas classes mais altas é produto dos números baixos de entrada das mulheres na carreira. No entanto, como se observa pelo gráfico a seguir, ponderadamente, as mulheres estão distribuídas entre as classes de maneira mais desequilibrada do que os homens, superando-os apenas nas três fases inferiores da pirâmide (de Terceiros a Primeiros-Secretários). As linhas de tendência do Gráfico 2 mostram que a desproporção das mulheres entre as classes é bem maior que a dos homens, com baixa composição delas entre as classes superiores.

${ }^{5}$ Em publicação na Revista da Associação dos Diplomatas do Brasil (ADB), Viviane Balbino relata que, segundo a Divisão de Pessoal do MRE, a proporção de mulheres entre os Ministros de Primeira Classe é de apenas 12\% (BALBINO, 2016). 
Trabalhos anteriores observam a existência de um gargalo a partir das promoções para a classe de Conselheiros (Gráfico 3) que afeta especificamente as mulheres (BALBINO, 2011; FARIAS \& CARMO, 2016). É a partir deste ponto da carreira que as conexões e a articulação política tornam-se mais relevantes para a aquisição das promoções (BALBINO, 2011). Sobre o assunto, Farias e Carmo (2016) verificam que, apesar de haver similaridade entre os gêneros dos diplomatas no que diz respeito a origem regional, formação educacional, classificação na Lista de Antiguidade, tempo no exterior e ocupação de cargos de chefia, a trajetória profissional das mulheres ainda é diferente da trajetória dos colegas do gênero masculino. Mas se as regras formais valem igualmente para homens e mulheres e se ambos preenchem os requisitos de habilitação para as promoções de maneira parecida, então o que explica o fato de que existe uma diferença de gênero na composição da hierarquia da carreira diplomática brasileira?

Conversando com várias diplomatas, a resposta provável, que já foi levantada outras vezes pela literatura (BALBINO, 2011; DELAMONICA, 2014; FARIAS \& CARMO, 2016), converge para a mesma explicação: a abertura do processo de promoções à escolha subjetiva dos diplomatas prejudicaria especificamente as mulheres. Como não existem parâmetros pré-estabelecidos para as votações nominais que acontecem ao longo de todas as etapas de composição do Quadro de Acesso, a seleção do voto fica a critério do julgamento individual de mérito por parte de cada diplomata participante.

Ou seja, a medida de subjetividade nas indicações abre espaço para que a cultura e a socialização dentro do Ministério assumam um papel fundamental na maneira como a hierarquia entre os diplomatas é constituída. Afinal, quando as instituições formais faltam, são as informais que se encarregam de moldar 0 comportamento dos indivíduos (HELMKE \& LEVITSKY, 2006). Este sistema de interação entre as normas formais do processo de concessão de promoções e as instituições informais e elementos de cultura e autoridade que pautam a socialização dentro do Ministério tem três consequências potenciais para as mulheres. 


\section{Gráfico 3. Distribuição de homens e mulheres entre as classes da carreira diplomática (dados de junho de 2015)}

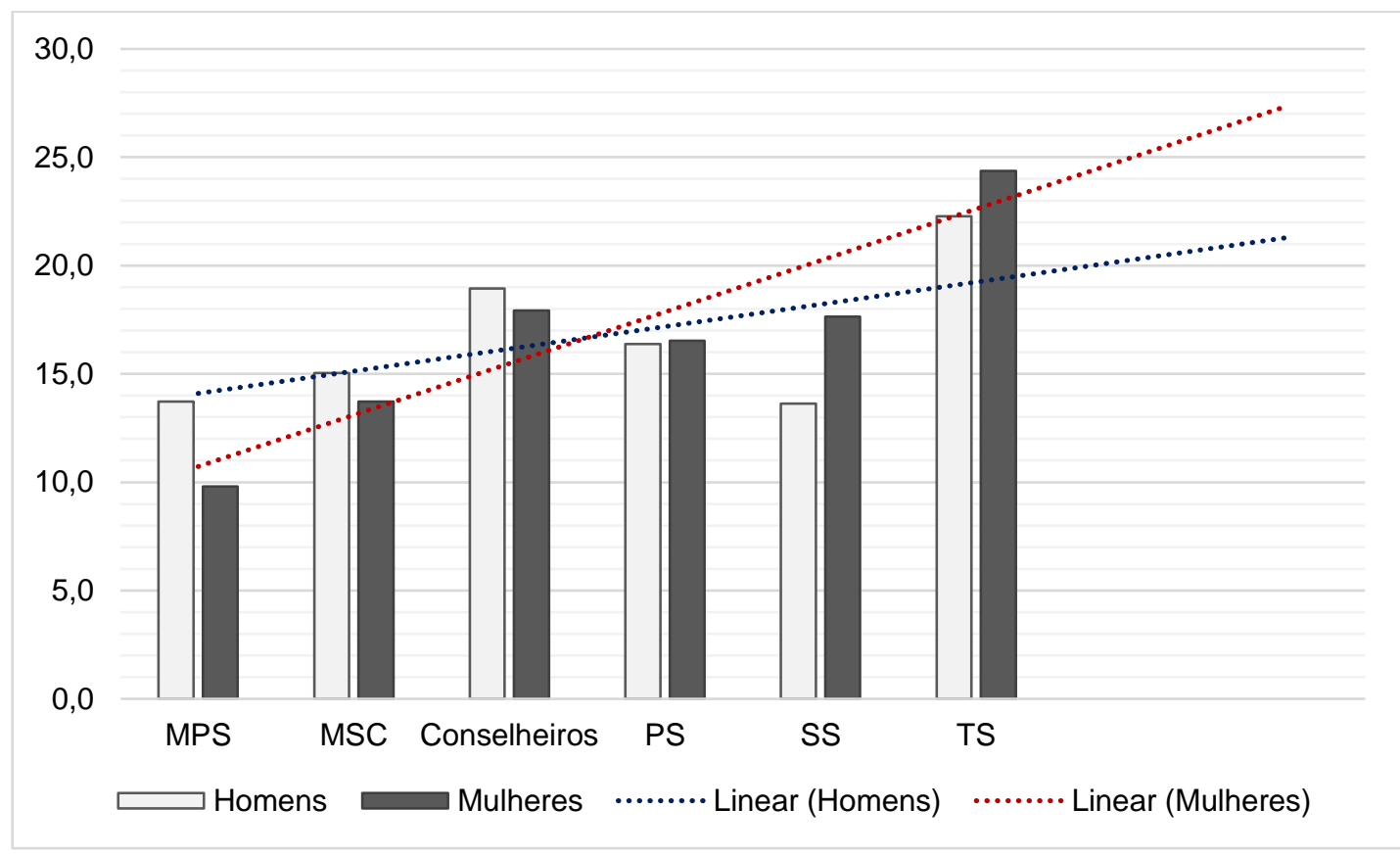

Fonte: Farias \& Carmo, 2016. Elaboração própria.

A primeira é a de que se abre espaço para que o favorecimento do padrão estético e social de representação da diplomacia brasileira. Aqueles que correspondem ao estereótipo dos "membros da Casa de Rio Branco" basicamente homens brancos, bem eruditos e de origem socioeconômica privilegiada - seriam favorecidos em detrimento dos demais. Considerando que a grande maioria dos diplomatas de fato corresponde a esta imagem (FARIAS \& CARMO, 2016) e que é natural que profissionais tendam a selecionar suas indicações com base em critérios subjetivos de similaridade à sua própria figura, é de se esperar que esse privilégio resulte em certa medida de exclusão para quem não possui as características daquele padrão (BALDER \& MCBRIER, 1997; BLAU \& DEVARO, 2006).

Em segundo lugar, a cultura e a socialização dentro do MRE, assim como em qualquer ambiente social, são permeadas pela divisão dos papeis de gênero, que determinam parâmetros distintos de comportamento, atitudes e aparência. Um exemplo muito claro, mencionado em comum nas entrevistas e em trabalhos anteriores, é sobre a percepção quanto à postura de imposição profissional: por 
exemplo, enquanto o homem que levanta a voz para seus colegas durante uma discussão é, geralmente, visto como alguém que "sabe se impor", a mulher que apresenta o mesmo comportamento é considerada "histérica" ou "desequilibrada" (Entrevistadas 2, 3 e 5; BALBINO, 2011).

Ou seja, determinadas posturas naturalizadas nas interações entre os homens, quando assumidas pelas mulheres, terminam por desqualificá-las (JOSHI, 2014). Estas diferenças constroem um sistema de avaliação de comportamento que funciona, como se diz popularmente, com "dois pesos e duas medidas". Este sistema é ainda mais problemático quando consideramos que os traços que correspondem ao referencial de liderança no ambiente de trabalho são tradicionalmente associados a elementos considerados masculinos.

Por fim, segundo a literatura, as conexões políticas, que começam a desempenhar um papel fundamental na promoção da visibilidade dos candidatos ao Quadro de Acesso, adequam-se mais ao perfil de interação social dos homens em comparação ao das mulheres (JOSHI, 2014). Com uma educação e sociabilização orientadas, entre outros elementos, pela competitividade, alguns estudos organizacionais indicam que os homens têm maior facilidade de arriscar, de estabelecer relações com colegas e de utilizar técnicas mais agressivas de autopromoção (GROWE \& MONTGOMERY, 2000; HOYTI, 2005; EAGLY \& CARLI, 2007; KIAMBA, 2008; VAZ, 2013). Do mesmo modo como ocorre nas competições eleitorais, a incongruência com o padrão masculino de competitividade desestimula a ambição feminina e põe a necessidade de articulação política como um obstáculo maior para as mulheres do que para os homens (NORRIS \& INGLEHART, 2004).

Dito isto, fica claro que o argumento meritocrático sobre o pressuposto de igualdade que o processo de ascensão oferece a homens e mulheres desconsidera não só que as experiências femininas e masculinas são distintas, como também os efeitos excludentes (ou, no mínimo, de desvantagem) que a subjetividade dos critérios tem sobre as mulheres na competição. Ainda assim, o discurso oficial de neutralidade do MRE parece ressoar bem entre os corredores da Casa e dificulta o reconhecimento da desigualdade na carreira diplomática (Entrevistadas 1, 3, 5 e 8). 


\section{Visibilidade da questão de gênero no MRE em anos recentes}

A questão da progressão tornou-se especialmente sensível dentro do Ministério a partir do período inicial da gestão do ex-presidente Lula, em 2003. $\mathrm{Na}$ época, o então Ministro de Estado, o embaixador Celso Amorim, instituiu uma política informal de cotas para as mulheres na composição dos Quadros de Acesso. Anteriormente, durante sua atuação de um ano e meio como Ministro de Estado na gestão de Itamar Franco, Amorim manifestou sua primeira mobilização em defesa de ações compensatórias à condição específica das mulheres na carreira.

Anteriormente, até os anos 1980, vigorou uma norma que instituía a obrigação de que, nos casais de diplomatas, caso estes desejassem permanecer juntos durante uma remoção, um dos cônjuges teria de entrar em licença durante o tempo que o outro permanecesse servindo no exterior. A prática da entrada neste tipo de licença ficou conhecida pela expressão "agregar". Naturalmente, quase a totalidade dos cônjuges que agregavam eram mulheres, o que provocava uma estagnação na contagem do tempo de carreira destas diplomatas que saem de licença - um dos requisitos para as promoções (BALBINO, 2011, p.51; Entrevistadas 1, 2, 3, 6 e 7).

A questão foi modificada no início do governo Sarney; no entanto, o tempo perdido pelas diplomatas que já haviam agregado não poderia ser contabilizado retroativamente. Diante da situação, na época do governo Franco, Celso Amorim relata que teve que persuadir sua assessoria jurídica para contar o tempo de serviço no exterior de algumas das diplomatas que agregara. $\mathrm{O}$ ex-chanceler conta que não pôde corrigir a situação de todas, mas que conseguiu reverter o prejuízo para algumas delas (Entrevista realizada com o embaixador Celso Amorim em 2016).

Amorim nota que, na época, já se preocupava com a situação das mulheres no Itamaraty, mas que o curto período de sua primeira atuação como Ministro inviabilizou a realização de mudanças estruturais. Só quando assumiu novamente a chancelaria, no início do primeiro governo Lula, resolveu interferir no QA:

Havia um funil. Primeiro [...], era essa questão de não poder servir no exterior e você dificultar que o casal seja [removido] junto [provoca], na sociedade brasileira, um prejuízo para as mulheres. [...]. Eu tinha 
consciência disso então eu passei, mais ou menos, a estabelecer umas cotas informais. Não posso dizer um número exato sempre, mas, sei lá, tinha seis, sete promoções, [aí] eu falava "quero pelo menos uma mulher". Na promoção, embora seja colegiado, o ministro tem um pouco mais de arbítrio, mas no Quadro de Acesso não. Então eu tinha que já garantir que no Quadro de Acesso entrassem [as diplomatas]. Eu tinha que falar, convencer os meus colaboradores de que era importante (Idem).

As cotas, então, utilizavam instrumentos de pressão interna para estimular as indicações das mulheres aos Quadros de Acesso. O ex-chanceler observa que, nesse processo, o então Secretário-Geral do Itamaraty, o embaixador Samuel Pinheiro Guimarães Neto, desempenhou papel importante na indicação das mulheres. Como a Comissão de Promoções é presidida pelo SecretárioGeral e não pelo Ministro ${ }^{6}$, Guimarães Neto encarregava-se de manifestar o desígnio do chanceler para os demais envolvidos no processo de formação do QA:

Então eu dizia "Samuel, são dez vagas no QA, eu quero pelo menos três mulheres, pelo menos". E ele executava (...), falava com cada um e dizia "olha, tem que ter três mulheres, senão o Ministro vai devolver o Quadro". Mas, claro, isso é uma coisa que você só faz em casos extremos, então todas as pessoas nomeadas, de alguma forma, por mim ou pelo Secretário-Geral acabavam se conformando (Idem).

A medida, como era de se esperar, encontrou resistência entre os diplomatas não só entre aqueles autodeclarados conservadores, mas até mesmo dentro de alguns setores da então dita "ala humanista" do Ministério:

...até [alguns diplomatas], entre aspas, que eu conheci progressistas, diziam "ah, mas eu não posso fazer isso, [a promoção] é só pelo mérito, [pel]a meritocracia". E eu dizia, "mas, gente, elas têm mérito, o problema é que elas não tiveram a mesma chance". [...]. Então você tem que compensar, não é? É que nem handicap de corrida, você tem que compensar as pessoas que têm menos chances (Idem).

Segundo Farias e Carmo (2016, p.39), entre 2003 e 2009 houve um "grande salto" da participação das mulheres no QA para a maior classe da carreira, iniciando na proporção dos $10 \%$ e chegando, durante o período, aos $29 \%$ - medida, inclusive, acima da proporção geral de mulheres na carreira. Entre a lista dos diplomatas que foram realmente promovidos, a proporção de

\footnotetext{
6 Segundo Amorim, para garantir que esse presidente seja "alguém da casa", já que o pertencimento à carreira diplomática é requisito obrigatório para ocupar o cargo de SecretárioGeral, mas não o é para o de Ministro das Relações Exteriores.
} 
mulheres cresceu de $16 \%$ para $29 \%$ no mesmo intervalo. Porém, após o término da gestão do presidente Lula, essas medidas começaram a reduzir. Em 2015, a taxa de participação feminina no QA para Ministros de Primeira Classe caiu para $18,6 \%$ e a proporção de mulheres que foram promovidas para a mesma classe reduziu para apenas $16,7 \%$ dos cargos.

Quando questionado sobre o motivo de as cotas não terem sido formalizadas, o embaixador Celso Amorim afirmou que:

Bom, eu não sou necessariamente contra, mas eu acho que se você puder resolver o problema sem criar uma coisa burocrática... Eu acho até que as mulheres se sentem melhor, pra falar a verdade [...]. Mas aí se a gente notar que vai haver retrocesso, então [restitui a] cota (Idem).

De fato, o retrocesso ocorreu. $\mathrm{E}$, em grande medida, a causa foi a resistência de boa parte dos diplomatas em reconhecer que existia uma diferenciação de gênero dentro do Itamaraty que prejudicava as mulheres nas promoções. Além da resistência dos homens, pesquisas anteriores identificaram que algumas das próprias diplomatas sentiram o peso desfavorável da "discriminação positiva".

Delamonica (2014) observa que algumas se sentiram "diminuídas com essa situação, como se a promoção decorresse não de sua competência e dedicação ao trabalho, mas do fato de ser mulher" (p.60). Já algumas das diplomatas que Balbino (2011) entrevistou confirmaram que existia, de fato, diferença no tratamento e julgamento de mérito das mulheres. Porém, elas acreditavam que as cotas não eram a resposta adequada à desigualdade; 0 ideal, para elas, seria que o tratamento paritário fosse estabelecido no dia-a-dia, sem instrumentos de discricionariedade.

Bem recepcionada ou não, a política de cotas aumentou a participação das mulheres nas classes superiores da hierarquia da carreira diplomática, mas esse aumento ainda não atingiu patamares de proporcionalidade à participação total das mulheres na carreira. Além disso, seu caráter informal permitiu que houvesse um retrocesso no crescimento dos índices participativos alcançados entre os anos de 2003 e 2009. Entretanto, o efeito principal, e que reverbera até hoje pelos corredores da Casa, certamente foi a visibilidade que a ação trouxe para a questão de gênero. Como veremos, as discussões e os posicionamentos 
que as cotas evidenciaram manifestaram-se com uma clareza crescente durante os anos subsequentes.

Um destes efeitos foi o de que, pela primeira vez, as diplomatas se organizaram em um grupo informal e de estrutura completamente horizontal para estabelecer uma agenda de interesses comuns às mulheres da carreira. Como fruto de reuniões não oficiais, o grupo entregou, em março de 2014, uma carta à chefia do Ministério, contendo quatorze pontos com reivindicações de adequação da estrutura e jornada de trabalho à experiência, também, das mulheres. A carta, subscrita por 203 diplomatas $^{7}$, trazia entre os destaques a demanda de que o Itamaraty buscasse adquirir o Selo Pró-Equidade de Gênero e Raça, compensação de reconhecimento do programa homônimo desenvolvido pelo governo federal em parceria com a Organização das Nações Unidas (ONU).

À época da $5^{\text {a }}$ edição do programa e como resultado da carta já mencionada, em 2014 o Itamaraty resolveu tentar obter este selo (apesar de alguma resistência remanescente de alguns membros do Ministério). Um dos requisitos para conquista do selo consistia na criação de um comitê voltado às questões de paridade entre homens e mulheres e de igualdade racial. Assim, em setembro do mesmo ano, foi criado o Comitê Gestor de Gênero e Raça (CGGR) do MRE.

A obtenção do selo pelas instituições é vinculada à elaboração e cumprimento de um plano de ação eficiente, que avalia as necessidades particulares de cada participante. Para que seja elaborado o plano de ação, é necessário que as instituições preencham a Ficha Perfil (FP), um registro que contém informações sobre funcionários, processos internos e práticas de promoção de igualdade ${ }^{8}$. Por conta disso, a primeira função fundamental do CGGR consistiu na elaboração dessa ficha, já que a portaria que criou o Comitê estipulou como única função a apresentação da candidatura do MRE ao programa.

\footnotetext{
${ }^{7} \mathrm{Em}$ número proporcional à distribuição das mulheres na hierarquia funcional.

${ }^{8} \mathrm{~A}$ Ficha Perfil contém sete áreas temáticas para preenchimento de dados: (1) perfil do corpo de funcionários, (2) processos de recrutamento e seleção, (3) de ascensão funcional e (4) de capacitação, além de (5) programas de saúde, (6) políticas de benefício, (7) mecanismos de combate a práticas discriminatórias e (8) o sistema de propaganda institucional.
} 
O preenchimento da ficha se mostrou uma tarefa mais ambiciosa que 0 previsto para o Comitê, pois o Departamento Pessoal do Itamaraty não dispunha de informações sobre a identificação racial dos funcionários, uma característica elementar à composição da FP. O desafio tornou-se ainda mais intrincado pois, segundo o formato tradicional dos requisitos de composição da ficha, era necessário que constassem informações sobre todos os funcionários que trabalham no Ministério, o que inclui diplomatas, oficiais de chancelaria, assistentes de chancelaria e funcionários administrativos. Para viabilizar esta tarefa, o CGGR adaptou a ficha de modo a incluir somente as três carreiras do Ministério: a de diplomatas, oficiais de chancelaria e assistentes de chancelaria.

Mesmo com a exclusão dos funcionários administrativos da FP, a agregação dos dados resultava em um banco de informações inconsistentes. Como o Comitê não encontrou uma maneira de uniformizar as informações que ou eram dispersas e continham lacunas ou não existiam -, optou-se por restringir ainda mais o formato da FP a apenas os funcionários da carreira diplomática. Como a prestação de candidatura ao CACD requeria a declaração racial, foi possível coletar as informações étnicas dos diplomatas. Ademais, ao longo do preenchimento da Ficha Perfil, um dos focos de observação centrou-se justamente em como as mulheres estavam ascendendo às classes mais altas: a questão da progressão funcional despontou como o principal ponto de desequilíbrio de gênero entre os diplomatas.

Quanto ao Comitê, o que parecia ser o momento adequado de abraçar a pauta de reivindicações por igualdade de gênero no Itamaraty rapidamente foi transformado no redirecionamento de suas funções para a questão de raça. No ano de 2015, em respeito à Lei oㅡ 12.990/2014, o edital do CACD foi lançado com a previsão de reserva de $20 \%$ das vagas para candidatos autodeclarados negros. Porém, nem o CESPE, órgão responsável pela elaboração do concurso, nem o próprio Itamaraty, contavam com banca examinadora da autodeclaração. $O$ resultado foi o aparecimento de casos polêmicos de incongruência na autodeclaração dos candidatos e pressão de ONGs do movimento negro, como a Educafro, para que o Ministério instalasse a banca de avaliação. Sob pressão do Ministério Público, que chegou a ameaçar suspender o concurso, o MRE cedeu, colocando o CGGR como instância responsável de verificação da 
autodeclaração racial do CACD. Assim, a questão de gênero assumiu papel secundário no Comitê.

Porém, em novembro de 2015 mais uma vez a questão de gênero ficou em evidencia. O gatilho das discussões foi a publicação de um artigo do internacionalista Matias Spektor, intitulado "Mulheres diplomatas", em sua coluna no jornal Folha de São Paulo. O texto, que se baseava na denúncia de que o machismo é institucionalizado dentro do Ministério, argumentava a existência de uma "ampla tolerância ao assédio e discriminação de gênero" na organização. Spektor também comentou sobre a resistência das promoções da gestão Amorim e o silêncio seletivo diante da promoção de homens "de sabida incompetência" (Entrevistadas 1, 2 e 3), com até mesmo a lotação de diplomatas com passagem pela polícia por agressão a colegas e/ou companheiras em cargos de destaque.

Segundo as diplomatas entrevistadas, o artigo causou um furor imediato pelos corredores do Itamaraty, provocando uma reação negativa por parte da chefia, que teria se sentido ofendida, enquanto instituição, e singularizada comenta-se que circulava o sentimento de "Criticam o MRE, mas e os outros ministérios? Só falam de nós?" (Entrevistada 1). Foi a partir das discussões levantadas pela publicação do artigo que as opiniões que tinham permanecido até então relativamente veladas se manifestaram de uma vez, ora através de uma indignação conservadora, ora por meio de declarações irascíveis, ofensivas e até mesmo misóginas em alguns casos.

Ainda sobre a reação oficial, esta foi reproduzida publicamente, quase duas semanas depois da divulgação do artigo, em uma nota redigida pela Assessoria de Imprensa do Ministério, na Folha de São Paulo. O Itamaraty não só contestou as denúncias, como manifestou que eram "claramente ofensivas à instituição" e que as afirmações de Spektor tinham sido realizadas sem qualquer fundamento.

A resposta oficial despertou indignação por parte das diplomatas. Através de um grupo de e-mail das mulheres da carreira, as diplomatas coletaram, em menos de 72 horas, 102 relatos de abusos que "vão desde as microviolências 
diárias a assédios sexuais, verbais e físicos"9. Todos os relatos foram compilados, preservando o anonimato das vítimas, em um documento que passou a circular abertamente entre os diplomatas. Segundo este documento, o objetivo de sua divulgação não era reivindicar reparação pelas agressões, mas contestar a postura de neutralidade assumida pelo discurso oficial do Ministério e desnaturalizar as práticas discriminatórias dentro do SEB.

Os relatos trazem um retrato das diversas dimensões através das quais a discriminação contra as mulheres é reproduzida nas dependências do MRE. Uma delas é a deturpação de funções profissionais por conta do gênero, como ter de servir café em conferências a pedido de embaixadores mais velhos, assistir à designação de alunas do IRBr como "dip ligs"10 de esposas de autoridades ou receber cobranças para participar da organização de eventos extraprofissionais (como chás de embaixatrizes, por exemplo). Além da descaracterização, muitas vezes as funções das mulheres são interrompidas por conta de seu gênero. Há vários relatos de diplomatas que foram excluídas de mesas de discussão sobre temas de quem eram "desks"11 para não constranger autoridades ou colegas, ou ainda porque seus chefes "presumiram" que elas se sentiram desconfortáveis pelo fato de serem as únicas mulheres nas mesas.

As duas práticas de rotina mais frequentes entre os relatos dizem respeito às manifestações explícitas de misoginia e à associação entre a aparência física e a competência. Várias mulheres comentaram sobre episódios em que os colegas lhe disseram que só foram promovidas por conta das cotas - uma chegou a ouvir de um colega que os homens não eram promovidos graças à "cota de mulheres" e à "cota gay". Comentários diversos como "tem coisa que só homem pode resolver", que "o problema do posto era o excesso de mulheres", que "mulher fala demais", além de referências a mulheres como "histéricas" e "loucas" também foram comuns.

\footnotetext{
${ }^{9} \mathrm{~A}$ existência da compilação dos relatos foi revelada a partir das entrevistas. Com o tempo, uma das diplomatas em contato com a pesquisa se dispôs a enviar o documento, que será utilizado adiante.

$10 \mathrm{O}$ dip lig é responsável por fazer a conexão entre delegações ou autoridades estrangeiras com instâncias do governo nacional.

11 Expressão utilizada para se referir ao (à) diplomata designado(a) como responsável por determinado tema.
} 
Em relação à aparência física, ela não só é associada à competência, como também a comentários apelativos à imagem e/ou sexualidade das diplomatas. Muitos relatos denunciavam o assédio sobre a forma "elogios" inconvenientes:

[...]. Despacho coletivo, todos os colegas em volta da mesa do chefe. Ele se dirige a mim com as seguintes palavras: "Nossa, você está um tesão de óculos" (Relato anônimo n²0).

Várias vezes entrei na sala de um chefe para [sic] despachar e ele pediu uma salva de palmas pela minha beleza... (Relato anônimo no 31).

[...] o embaixador nos "late sixties" exclamando, ao entrar na sala (compartilhada): "cadê aquela gata que fica aqui?". (Relato anônimo $\mathrm{n}^{\circ}$ 24).

Uma vez, fui despachar, no dia seguinte a um evento, e meu chefe virou pra mim e disse: você ontem estava muito gostosa... (Relato anônimo no 99).

Durante uma aula no $\mathrm{IRBr}$ resolvo fazer uma intervenção sobre o tema em debate. Ao final da aula, o professor me interpela para dizer o seguinte: "Ótima observação. Como é que uma mulher bonita pode ser também inteligente?". (Relato anônimo n ${ }^{\circ}$ ).

Outros denunciavam a instrumentalização da beleza e do corpo das funcionárias:

[...] o diplomata estrangeiro se insinuou e fez gracejos inapropriados. Ao cumprimentar meu chefe, agradeceu a recepção e disse que era muito bom ser recebido por uma diplomata tão bonita. Meu chefe sorriu orgulhoso, e comentou que ele merecia ser muito bem recebido, levando a crer que esse tinha sido exatamente o motivo para me designar a tarefa (Relato anônimo no 63 ).

Ser chamada à sala do chefe e levar o bloco de anotações toda disposta a anotar as instruções do despacho e ouvir: "não é nada, só te chamei pra [sic] enfeitar minha sala" (Relato anônimo $n^{\circ} 6$ ).

As experiências narradas não incluíram só manifestações verbais abusivas. Houve também relatos de contato físico ou insinuação sexual direta:

Duas vezes tive que aguentar embaixador bêbado amassando minha perna por baixo da mesa em jantar de trabalho. Uma foi meu então chefe, outra um embaixador estrangeiro, aproveitando que não dava pra [sic] trocar de lugar (Relato anônimo no 10).

Bem, eu tive Embaixador tocando minha perna embaixo da mesa, Presidente (da República!) ligando para minha casa para me convidar para um cineminha no Alvorada, Senador me pedindo para acompanhá-lo em um jantar depois da reunião, só que o jantar era a dois... [...] (Relato anônimo no 72).

Missão eventual com o chefe. Chegamos ao hotel e ele diz "Olha só que pena, o hotel está cheio, vamos ter de dividir um quarto". Vou em 
direção à saída, pronta para procurar outro hotel, e ele "Calma, era só brincadeira". [...] (Relato anônimo $\mathrm{n}^{\circ} 72$ ).

O vazamento interno do documento impactou profundamente o Itamaraty e colocou a chefia em uma posição que requeria, no mínimo, o reconhecimento de que os casos narrados condiziam com as denúncias trazidas por Spektor.

Segundo relatos, o Secretário-Geral da época, o embaixador Sérgio Danese, impactado pela questão, acionou o Comitê Gestor de Gênero e Raça e solicitou uma reformulação de suas atribuições, ampliando sua atuação. Em um primeiro momento, houve a demanda de que o CGGR se tornasse uma espécie de ouvidoria do Ministério. Mas a simultaneidade da demanda de raça, como a comissão verificadora da autodeclaração no processo de entrada, em concomitância com a questão de gênero, terminou sobrecarregando a instância, de tal modo que o plano de candidatura ao Programa Pró-Equidade deixou de ser sua diretriz fundamental.

Alguns membros do Comitê - não se sabe se a totalidade - aprovou a ideia de criação de uma ouvidoria, mas acreditavam que não cabia ao CGGR assumir esse papel como função secundária. E naquela carta apresentada pelo grupo de mulheres, em março de 2014, já havia a recomendação de criação de uma instância autônoma dedicada a tratar exclusivamente do assunto. De toda forma, atualmente tramita a sugestão do próprio Comitê de que ele sirva como uma espécie de caixa postal de denúncias de discriminação, que seriam, então, encaminhadas à Corregedoria e à Comissão de Ética - únicos órgãos atualmente disponíveis para julgar casos de assédio e discriminação contra as mulheres, entre os diplomatas.

Diante do decorrer dos fatos e de novas demandas, o Comitê, do qual fazem parte não só diplomatas, mas também oficiais e assistentes de chancelaria, além de funcionários homens do SEB, encontra-se em fase de redefinição. Passado o período de turbulência quanto à questão, que ainda mexe com os ânimos dos diplomatas, acredita-se o CGGR será novamente reestruturado (Entrevistada 2).

Uma das questões relacionadas ao Comitê é a de que este teria virado uma espécie de "bandeira" da atenção do Ministério com o assunto 
(Entrevistadas 1, 2 e 3). Uma das diplomatas entrevistadas observa que "O Comitê foi criado justamente para fiscalizar, para avaliar, para fazer a reflexão interna. Mas até agora infelizmente há essa impressão de que a criação do Comitê é um fim em si" (Entrevistada 1).

Os relatos refletem que ainda há grande resistência por parte dos diplomatas em aceitar que existe discriminação de gênero no Itamaraty. Até hoje a vigência das cotas informais durante a chancelaria de Celso Amorim, mesmo com sua implementação eliminada depois da saída do embaixador do cargo, gera comentários depreciativos sobre o movimento organizado das mulheres. Parte do discurso que nega as diferenças de gênero no Itamaraty é pautado na ideia de que algumas diplomatas "só querem ter uma promoção mais fácil" (Entrevistadas 1, 2 e 4).

Várias entrevistadas comentaram que, em geral, as mulheres não se sentem confiantes nem confortáveis para recorrer às vias atuais da Corregedoria ou da Comissão de Ética. O medo de retaliação e de que a carreira, "que é bastante baseada na aparência e na conduta" social (Entrevistada 3) fique marcada por uma denúncia a um colega faz com que várias mulheres resolvam tolerar ou anistiar episódios de assédios e/ou discriminação (Grupo focal; Entrevistadas 1, 3, 4, 6, 7). Além disso, algumas relataram ter tomado conhecimento de casos de diplomatas denunciantes que sofreram perseguição pelos aliados do acusado, tendo sua carreira perenemente prejudicada (Entrevistadas 2 e 8).

\section{Considerações finais}

Em meio aos relatos apresentados, ficou claro que as diplomatas, diante da resistência persistente da maioria de seus colegas em reconhecer as especificidades de suas experiências enquanto mulheres, desafiam cada vez mais paradigmas da Casa e suas expectativas de gênero. A organização informal destas mulheres se apresenta hoje como uma das estratégias mais relevantes de reivindicação de uma agenda feminina na carreira. Assim, o primeiro passo deste processo parece consistir em gerar visibilidade para as experiências e para as dificuldades específicas enfrentadas pelas mulheres. 
Esta lógica serviu de base para a instituição das cotas informais para mulheres, na elaboração dos Quadros de Acesso durante a gestão do exchanceler Celso Amorim, bem como para a mobilização das mulheres que eventualmente culminou na criação do Comitê Gestor de Gênero e Raça. O posicionamento que os membros do Itamaraty vinham demonstrando desde a instituição das cotas foi refletido pelo posicionamento oficial do Ministério, quando as experiências de discriminação das diplomatas foram levadas a público na voz de Matias Spektor. Em reação quase imediata, mais uma vez as diplomatas negaram a neutralidade de gênero na carreira, divulgando suas experiências e demandando reconhecimento.

Portanto, apesar dos avanços recentes quanto à visibilidade da questão de gênero na Casa, o processo de mudança é vagaroso e parece enfrentar a resistência de muitos. O medo do Itamaraty da particularização de seu caso também é um grande desafio na busca pela igualdade de gênero entre as diplomatas.

E não é que o MRE acolha e perpetre a desigualdade entre homens e mulheres mais ou menos do qualquer outro ministério do Governo Federal. Porém, o reconhecimento de cada uma das maneiras peculiares através das quais as hierarquias de gênero se manifestam dentro de sua estrutura burocrática é fundamental para que as mudanças necessárias para a inclusão das mulheres sejam instituídas nas práticas e na rotina organizacional do órgão.

O machismo passa a ser institucionalizado quando é reproduzido em regras e normas formais e informais: quando o montante das experiências das mulheres mostra que a discriminação não é pontual, mas sim vivenciada por um número expressivo de diplomatas; que não existem vias que protejam, de fato, as vítimas de discriminação e assédio no ambiente de trabalho; e que a ausência de vias punitivas efetivas permite a existência de casos em que um profissional envolvido em diversos episódios de agressão contra as colegas seja recompensado ${ }^{12}$.

${ }^{12}$ Todas as entrevistadas mencionaram o caso do profissional conhecido entre os corredores pelo apelido "Faca", envolvido em inúmeros casos de agressão contra mulheres dentro e fora do ministério, entre os quais o último episódio foi sucedido tanto pela impunidade do caso, quanto pela promoção do agressor. 
Se as cotas informais geraram e ainda geram tanta indignação por parte de vários diplomatas, o mesmo não parece acontecer frente às evidências de que esta estrutura existe. Diante dos eventos descritos, dos relatos compilados pelo grupo de mulheres e das narrativas das diplomatas entrevistadas, fica claro que uma das mudanças mais fundamentais consiste na criação de um canal institucional voltado especificamente para o recebimento e apuração das denúncias de assédio.

Caso seja criado, a eficiência deste canal institucional dependeria da garantia de preservação dos denunciantes, além de sua efetividade na implementação de constrangimentos e punições adequadas. Idealmente, seria recomendável que esta instância atuasse com determinado grau de autonomia e que seus membros não fossem, também, profissionais de qualquer carreira do MRE.

Uma mudança institucional do tipo depende do reconhecimento efetivo das discriminações e dos assédios como problema relevante. Tal mudança surgirá da constatação de que as regras formais que regimentam 0 funcionamento do Itamaraty estão mergulhadas em um amplo contexto de regras informais e de aspectos de cultura e socialização que mantêm as hierarquias tradicionais de gênero.

O próprio processo de concessão de promoções possui regras que estabelecem o teto de vidro da carreira para as mulheres. Segundo todas as entrevistadas, a medida de discricionariedade que o regimento das promoções atribui aos diplomatas concede espaço para que a dinâmica das hierarquias de gênero se reproduza na exclusão das mulheres das camadas mais altas da carreira.

Apesar de os trabalhos anteriores e das entrevistas realizadas com as diplomatas apontarem nesta direção, não se pode inferir se, de fato, este prejuízo se reproduz na prática do Itamaraty. Desenhos longitudinais de experimentos ou estudos de caso em profundidade - com a quantificação de variáveis relacionadas aos critérios mais citados pelos diplomatas ou com uma análise das redes de conexões políticas internas - podem comprovar se as mulheres são afetadas negativamente pela ausência de critérios nas votações/indicações. Este trabalho, então, em seu caráter exploratório, deixa como agenda de 
pesquisa a possibilidade de realizar uma avaliação institucional dos mecanismos de promoção na carreira diplomática que comprovem se estes promovem e sustentam a desproporção de gênero nas classes mais altas da hierarquia da carreira diplomática.

\section{Referências}

BALBINO, Viviane Rios. Diplomata: substantivo comum de dois gêneros. Brasília: Fundação Alexandre de Gusmão, 2011.

. Mulheres no MRE. Revista da ADB, Edição 92, 2016.

BLAU, Francine D.; DEVARO, Jed. New evidence on gender differences in promotion rates: An empirical analysis of a sample of new hires. Industrial Relations: A Journal of Economy and Society, v. 46, n. 3, p. 511-550, 2007.

BRELAND, Hunter M.; KUBOTA, Melvin Y.; BONNER, Marilyn W. The performance assessment study in writing: Analysis of the SAT II: Writing Subject Test. ETS Research Report Series, n. 2, 1999.

CHEIBUB, Zairo Borges. A carreira diplomática no Brasil: o processo de burocratização do Itamarati. Revista de Administração Pública, v. 23, n. 2, p. 97128, 1989.

DELAMONICA, Laura. Mulheres diplomatas brasileiras. 2014, 82 f. Dissertação (Mestrado em Relações Internacionais), Universidade de Brasília, Brasília. 2014.

DULCI, Tereza Maria Spyer. Revista de História, n. 158, p. 315-318, 2008.

EAGLY, Alice Hendrickson; CARLI, Linda Lorene. Through the labyrinth: The truth about how women become leaders. Boston: Harvard Business Press, 2007.

FARIAS, Rogério; CARMO, Géssica. As mulheres na carreira diplomática brasileira: uma análise do ponto de vista da literatura sobre mercado de trabalho e gênero. Mundorama, jan. 2016.

GROWE, Roslin; MONTGOMERY, Paula. Women and the leadership paradigm: Bridging the gender gap. The Phi Kappa Phi Journal, 17E, p. 1-10, 2000.

HELMKE, Gretchen; LEVITSKY, Steven. Informal institutions and democracy: Lessons from Latin America. Baltimore: The John Hopkins University Press, 2006.

HOYT, C. L. The role of leadership efficacy and stereotype activation in women's identification with leadership. Journal of Leadership \& Organizational Studies, v. 11 , n. 4, p. 2-14, 2005.

IBGE - Instituto Brasileiro de Geografia e Estatística. Síntese de indicadores sociais. Rio de Janeiro: Centro de Documentação e Disseminação de Informações, 2011. 
IRBr - Instituto Rio Branco (Ministério das Relações Exteriores). Breve história do Instituto Rio Branco. Disponível em: $<$ http://www.institutoriobranco.mre.gov.br/pt-br/o instituto.xml>. Acesso em 18 de janeiro de 2017.

Anuário do Instituto Rio Branco - 2015. Brasília: Instituto Rio Branco, 2016. Disponível em: <https://sistemas.mre.gov.br/kitweb/datafiles/lRBr/ptbr/file/Anu\%C3\%A1rio\%202015(1).pdf>. Acesso em 19 de janeiro de 2017.

Anuário do Instituto Rio Branco - 2014. Brasília: Instituto Rio Branco, 2015. Disponível em: <https://sistemas.mre.gov.br/kitweb/datafiles/lRBr/ptbr/file/Anu\%C3\%A1rio\%202014.pdf>. Acesso em 19 de janeiro de 2017.

Anuário do Instituto Rio Branco - 2013. Brasília: Instituto Rio Branco, 2014. Disponível em: <https://sistemas.mre.gov.br/kitweb/datafiles/lRBr/ptbr/file/anuarios/Anu\%C3\%A1rio\%202013 FINAL.pdf>. Acesso em 19 de janeiro de 2017.

Breve história do Instituto Rio Branco. Disponível em: $<$ http://www.institutoriobranco.mre.gov.br/pt-br/o instituto.xml>. Acesso em 2 de fevereiro de 2017.

JOSHI, Aparna. By whom and when is women's expertise recognized? The interactive effects of gender and education in science and engineering teams. Administrative Science Quarterly, v. 59, n. 2, p. 202-239, 1 jun. 2014.

KIAMBA, Josephine M. Women and leadership positions: Social and cultural barriers to success. Wagadu, v. 6, p. 5, 2008.

KIZILCA, F. Kemal. Standardized test-based student selection and gender differences in academic achievement. "IS, GUC" Industrial Relations and Human Resources Journal, v. 15, n. 4, p. 102-115, 2013.

MAIA, Melina Espeschit; ALVARENGA, Tainá Guimarães. Marias do Brazil. As mulheres e a diplomacia pelo olhar das Embaixadoras do Brasil na ONU. Jucá, n. 4, p. 30-39, 2010.

MOURA, Cristina Patriota de. O Instituto Rio Branco e a diplomacia brasileira: um estudo de carreira e socialização. Rio de Janeiro: Editora FGV, 2007.

. O inglês, o parentesco e o elitismo na Casa de Rio Branco. Cena Internacional, v. 8, n. 1, p. 20-34, 2006.

NORRIS, Pippa; INGLEHART, Ronald. Cultural barriers to women's leadership: A worldwide comparison. Journal of Democracy, 2004.

PIFFER, Davide; PONZI, Davide; SAPIENZA, Paola; ZINGALES, Luigi; MAESTRIPIERI, Dario. Morningness-eveningness and intelligence among highachieving US students: Night owls have higher GMAT scores than early morning types in a top-ranked MBA program. Intelligence, v. 47, p. 107-112, 2014.

SPM - Secretaria Especial de Políticas para as Mulheres. Programa PróEquidade de Gênero e Raça. Rompendo fronteiras no mundo do trabalho. Brasília: SPM, 2016. 
VAZ, Daniela Verzola. O teto de vidro nas organizações públicas: evidências para o Brasil. Economia e Sociedade, v. 22, n. 3, p. 765-790, 2013.

Recebido em 24 de abril de 2017. Aprovado em 06 de agosto de 2017. 